\title{
The moment of play and movement: A qualitative study of children's playful shared movements
}

\author{
Lillian Pedersen \& Vegard Fusche Moe \\ Western Norway University of Applied Sciences
}

\begin{abstract}
The aim of this article is to investigate children's playful shared movements on the preschool playground and to understand their doings when they perform apparently new and unexpected movements in these meetings. Video observations and field notes from two preschools constitute the empirical material, and we have analyzed three situations from the video observations to investigate the research question. The findings indicate that children in playful movement interactions use their habits to create moments that introduce something new and unexpected, what Stern (2007) conceptualizes as critical now moments. These now moments are opened up by imaginings, transformations, and excitement. In these moments, children can be creative and curious, leading to opportunities to experience growth in how they use their body and the place. Whether now moments led to creativity, growth and development, seemed to depend on the emotional attunement between the participants.
\end{abstract}

Keywords: Outdoor play; phenomenology; habits; now moments; moments of meeting

Received: March, 2020: Accepted: September, 2020: Published: December, 2020

\section{Introduction}

Children's lives in contemporary societies are increasingly organized, and children are more sedentary than ever before (World Health Organization [WHO], 2019, p. 1). From the UN Committee on the Rights of the Child's (2013, p. 12) point of view the trend is clear: Nations appear to give priority to academically targeted plans and actions to create modern knowledge societies, and on this basis they express concern for children's opportunities to play and be physically active. The consequence of this preference may be that movement, the body, and free play are partially left behind. Although there are signs that movement and play are being moved up on the agenda, they are often seen as an instrument for improving children's health or

\footnotetext{
^Correspondence: Lillian Pedersen, e-mail: lillian.pedersen@hvl.no
} 
academic opportunities later in life (Alexander et al., 2014, 2015; Petrie \& ClarkinPhillips, 2018). However, play and movement have intrinsic value. In playful movements, children discover who they are and how they can explore themselves and their surroundings as embodied beings. Play and movement are thus about basic living conditions. Winnicott's (2005, p. 56) theories about play emphasize this point. He claims that playing is the natural attitude for children. Play facilitates children's growth, their mutual understanding of a task, and often elicits a shared enthusiasm. In play, children can be creative and use their whole personality to grow (Winnicott, 2005, p. 71). Stern (2010, p. 9) adds the importance of movement for these growth and self-discovering processes to occur. He conceptualizes it as moments of movement, and argue that these moments open up the possibility for a reorganization of the intersubjective field and a change in the forms of vitality (Stern, 2007, p. 169-180, 2010, p. 7-17). Both Winnicott and Stern highlight the importance of intersubjectivity and affectivity for humans possibillities to experience creativity and growth.

In this article, we will investigate children's playful shared movements in preschools. Our specific objective is to explore, in depth, apparently new and unexpected playful movement situations between children and between children and the staff on the preschool playground. We believe that these situations are important for better understanding children's participation in playful movement activities. Events like these may open up new worlds to children, but they can also cause them to withdraw from the activity. A better understanding of this dimension is central to meeting preschool children on their own terms, and probably crucial if preschools are to be a place of growth and enrichment.

Before we move further into the topic, a couple of conceptual clarifications are needed. We use the concept 'play' to refer to activities that are "driven by intrinsic motivation and undertaken for [their] own sake, rather than as a means to an end" (UN Committee on the Rights of the Child, 2013, p. 5). These are activities children themselves have decided to participate in. With the term 'playground' we refer to the outdoor environment that is right outside of the preschool building. We chose to investigate the playground because it is considered an area where children can play and move freely (Bjørgen, 2012). The study is inspired by phenomenology, and a particular feature of phenomenology is the emphasis on the lifeworld as crucial to understand human experiences and intentions (Husserl, 2004, p. 43). In line with Merleau-Ponty (2012, p. 54-56, p. 102), we understand movement as the body's dynamic response to environmental requirements and conditions, and that perception is oriented towards the environment and what is experienced as "a truth" for the moving subject. The Canadian philosopher Mooris (2004) developed Merleu-Ponty's ideas about the dynamical relationship between intentions, movement and the enviroment. And in line with his ideas, we understand growth and creativity in movements as connected to changes in the human's sense of the environment. We connect this to Stern's (2010, p. 3-17) concept forms of vitality. He understands forms of vitality as physical affective patterns that is dynamic, provides us with a context and 
enable us to be engaged in relations to other people. These patterns are expressed as our bodily rhythm, and it is on the basis of these we react in a certain emotional way. They give meaning to the specific situation.

The empirical material consists of video observations and field notes, and we will present three situations from the video observations to investigate the following research question: What characterizes apparently new and unexpected playful shared movements between children and between children and staff on the preschool playground? The observations are analysed using thematic analyses and these are influenced by Stern's (2007) concepts of now moments and moments of meeting and Morris' (2004) open and closed body posture. In the following, we will use previous research to characterize what we know thus far about children's playful shared movements.

\section{Children's playful shared movements}

Play researcher Sutton-Smith (1997/2001) emphasizes the paradoxical nature of play, an ambiguity that makes the concept difficult to define. As the German philosopher Gadamer underlines, play is not static, but is in a continuous to-and-fro motion (Gadamer, 1975/2006, p. 105).

Mårtenson (2004) used an environmental psycological approach to study preschool children's outdoor play in a Swedish context. Her findings indicate that children most often structure their play activities towards a common purpose. Flanningan and Dietze (2017) extend this understanding. They studied children's use of loose parts in a natural outdoor environment and found that the play's symbolic transformations functioned as the coordinating element for the realisation of the purpose of the play. In play, children explore the space between the real and the imaginative world (Kristensen \& Greve, 2018). When children play, they often imagine they are someone other than who they are in the real world, and they transform the material and the place to fit into their play imaginings.

When it comes to playful imaginative shared movements, Løndal (2010) has studied this phenomen by using Merleau-Ponty's (2012) and Morris' (2004) phenomenology as a theoretical perspective. He found that children usually imitated each other or tried out movements together, and that this promoted exploration in the sense that it allowed children to use their body and surroundings in other ways than they would normally. Thus, playful shared movements can promote and develop a motivating culture for movement play (Bjørgen \& Svendsen, 2015) and physical challenges (Haywood-Bird, 2017). In addition, Robertson, Morrissey and Moore (2019), when they examined children's sociodramatic play outdoors, found that it was also the other way around; that the children's opportunities to move freely opened up for participation in playful shared movements.

Teachers' involvement in child-managed play is found to be positive for children's participation in movement play (Hagen, 2015). When staff show interest and express warmth and involvement, children's stamina for movement exploration increases (Bjørgen, 2016). If, on the other hand, teachers do not understand the situation 
correctly or are not involved, it can spoil the movement exploration (Morrissey et al., 2017) and growth (Karlsen \& Lekhal, 2019).

The opposite also seems to be true. Participating in play that allows them to explore and expand their movements creates emotionally positive encounters for children. For instance, children who participate in play where they can experience bodily challenges and experience risk can create thrilling emotions (Sandseter \& Kennair, 2011). On the one hand, play seems to create moments where children can meet each other in movement, and on the other hand, these shared movements seem to create emotional moods that encourage creativity and exploration. Karoff (2013) used Bateson's term of "framing" when she examined the relation between play practices and play moods, and she claim that the mood that is created among the participating children, seems to be essential to determining what kind of play and movement they can create.

Previous research indicates that children's participation in playful shared movement situations open up for exploration, creativity, growth and change. It seems like there is something about playful shared movements that promotes what authorities are looking for in their academic plans and actions: growth and change in children's actual knowledge and experiences. This made us curious about what this something is. Moreover, and in line with Karlsen and Lekhal (2019), we find that there is a lack of in-depth studies that focus on what happens when playful shared movements in preschool open up into something apparently new and unexpected for children. We will start our exploration with a phenomenological approach to movement and emotions.

\section{Movement and moment}

Morris (2004, p. 126-127) uses the concepts 'envelope' and 'depth' to describe human development, and he considers physcial and cognitive development as interdependent. From his point of view the body-world movement generates envelopes of perception: “... an inner envelope in relation to the body as place, an outer envelope in relation to larger place" (Morris, 2004, p. 126). Our sense of depth, what we find meaningful, are expressed in terms of these envelopes, and what opportunities we have to develop our bodily movements are essential for our creation of envelopes.

Morris considers that movement develops along a continuum from basic movement skills to movements adapted to particular contexts that eventually become part of each individual's movement skills and style - what can be termed idiosyncratic movements (Morris, 2004, p. 94). This process is dynamic: the mover goes back and forth along the continuum, and when his or her movement habits are challenged, the movement abilities and the characteristics of the continuum will change. The movement continuum is the habitual part of movement and it is expressed in the way children move their bodies and how they use the playground. It develops on the basis of how children experience themselves, others and the world in a mutual relationship. Habits are a kind of frozen armor that is on the verge of thaw and change. As Morris 
underlines, "habit as freezing out shock contains the seeds of new shock that lead to thaw and reform" (2004, p. 90).

Shock occurs when the world and others draw us into engagements that provoke a breakdown of movements (Morris, 2004, p. 98). Movements that change our understandings of ourselves, others and the surroundings. This means we cannot understand the expansion of habits as merely an inner psychological state of mind; rather, we must recognize it as something that takes place in our engagement as beings.

Stern conceptualizes the change in habits as a now moment that opens up an opportunity for a reorganization of the intersubjective field and a change in feelings of vitality (Stern, 2007, p. 169-180; 2010, p. 7-17). A now moment is a moment where something new, unexpected, problematic or worrisome occurs. It is a moment in the flow of ordinary everyday moments that creates a tension in us. For instance, someone using a football in a way that differs from how it usually is used. This can become a now moment that creates a moment of meeting, creativity, and change. Whether or not this happens depends on what emotions, affective attunement and vitality forms are created (Stern, 2007, p. 236).

Feelings of vitality are physically dynamic patterns of events that are found inside us all of the time. Stern argues that vitality has three possible forms: exploding, pulsing, and fading. Exploding is a sudden increase in intensity, pulsing is dynamic and has medium intensity, and fading involves a sudden decrease in intensity. Together, these forms of vitality create a pattern, expressed as the rhythm of the body (Stern, 2010, p. 88). Feelings of vitality are awakened or affected by other people's behavior and by changes in motivation, desire, and excitement. A child's movements depend on the pattern of the vitality forms and the emotional state of his or her interactions. For instance, distress can lead to a closed body posture and a feeling of "I can't," whereas the absence of distress may lead to an open body posture and a feeling of "I can" (Morris 2004, p. 162). Playful shared moments can remain movements that last for only a fleeting moment in time or they can turn into new ways of understanding the body, others, and space.

\section{Methods}

The fieldwork was conducted by the first author in two preschools. In this section, we explain how the empirical material was collected and analyzed. We also describe the scope of the video observations and the field notes and provide information about the participants.

\section{Researching everyday movements}

Our methodological approach is inspired by Fangen's (2010) three levels of interpretation. These levels involve bringing forward both closeness to and distance from the empirical material. To create closeness to the material, we highlighted sequences that 
appeared in the video observations, field notes, embodied experiences and memories on a descriptive level. To create distance, we first used phenomenological perspectives and concepts on movement and the moment, and then discussed them in relation to prior research on playful shared movements.

When Corsaro (2003, p. 8) sought insight into children's perspectives, he assumed a role that made him different from other adults. In this case, carrying a camera and a notebook marked the researcher as different from the preschool staff. In addition, as long as the children were not in danger, the researcher did not set limits for them. She interacted with the children and the preschool staff as little as possible. Hence, she talked to them only when they initiated a conversation, and she did not participate in the activities. She informed the preschool staff and the children before the fieldwork began that she would assume this stance.

\section{Participants}

We have named the preschools preschool 1 and preschool 2. In both, the playgrounds are about 1,000 square meters and contain both play equipment and natural elements, such as trees, grass, hills, and small wooded areas. These characteristics make them representative of Norwegian playgrounds (Moser \& Martinsen, 2010). In both playgrounds, about 40 children play at the same time.

Because we seek insight into children's playful shared movements, understanding their actions in their entirety and in depth is crucial. Thus, the observations focused on particular children - two girls and two boys at each preschool. Nevertheless, the observations often involved several other children, who were included in the transcripts but remained in the background of the analysis. We focused on five-year-olds because we assumed they would engage in a greater variety of movement practices than younger children and thus could better illuminate the characteristics of playful shared movements. In addition to representing both sexes, the selected children preferred different activities. They were selected based on the pilot study and after discussions with the preschool teacher.

\section{Video Observations and Field Notes}

The fieldwork lasted for two weeks at both preschools, one week in January and the other in April. In Norway, weather conditions are quite different in winter and in spring/summer, and we wanted insight into activities in both seasons. Before the fieldwork started, the first author conducted a pilot study with two main objectives: to ensure that the camera and the field notes were appropriate for the task, and to ensure that the observations would illuminate the research question.

The first author decided to film the observations because it allowed her to rewatch them several times. The video recordings were used as a tool to increase the robustness and the depth of the analysis (Walsh et al., 2007). The researcher focused on one or two of the children each day, videoing as long as the memory card lasted; most of the recordings were 20 minutes long. She filmed about two hours daily, accumulating 
a total of approximately 40 hours of film, and wrote field notes to provide a context for each video (Walsh et al., 2007). The notes were primarily devoted to her role as researcher, as well as her thoughts and emotions concerning the participants who were being observed (Løkken, 2012, p. 77). They also included information about the weather and the preschool's daily rhythm.

\section{Transcript and Analysis}

Because children's movements were an important element of this study, the opportunity to connect the videos and the transcripts was crucial. NVivo Version 11 was therefore used to transcribe the content of the videos, as well as to analyze the videos and the field notes. In addition, details and connections between elements from the observations and between the observations and the field notes were written down with pen and paper.

In the analysis, the first author focused on situations where the children

- were in playful activities, i.e. freely chosen activities without predefined goals;

- used gross motor movements such as climbing, kicking, throwing, and cycling in a playful way;

- interacted with other children or/and preschool staff;

- were drawn towards something apparently new and unexpected and moved in a way that could be characterized as unstable or/and exploratory.

She found 35 situations that met all four criteria.

The analysis approach was inspired by Braun and Clarkes' (2006) six phases of thematical analysis. In the first phase, the researcher familiarized herself with the data by watching the recordings of the observed situations and reading the field notes several times. In the second phase, she identified patterns across the situations. The main finding in this phase was that when a new and unexpected behavior occurred, it could be huge and visible or small and difficult to spot. In both instances, it happened in a moment of time. The first author found Stern's concept now moment, to be illustrative for how she read the situation. In phase three, she performed a micro analysis where she used the concept now moment as a filter. She found that the creation of now moments, most often was connected to the children's opportunities to experience imaginings and transformations, and that they could explore the imaginings and transformation on the basis of their habits. The imaginings and transformations seemed to excite the children in a way that altered their habitual movements. We have thematized this as the role of habits, imaginings, transformations and excitement for now moments to occur. Another pattern regarding the now moment emerged in this phase. It could either lead the children into further exploration of the new and unexpected of the situation or it could make them to withdraw from the activity. In phase four, both authors reviewed the micro analysis based on this finding and searched for a theoretical framework that could help us to further understand what happened when the children continued the exploration. We found Morris' (2004) open and closed body 
posture and Stern's (2007) moment of meeting as helpful conceptualizations since they focus on the emotional states of the interactions. Based on these concepts, Morris and Stern argue that intersubjective processes are essential for our bodies to open up to challenges. Thematically we have conceptualized this process of opening up to challenges as a moment of shared feelings. In phase five, we linked the findings and the theoretical concepts. The final phase of the analysis was to compose a report of the findings that would be understandable to a reader.

\section{Trustworthiness - Ethical Considerations}

The credibility and trustworthiness of qualitative studies can be enhanced by making the research process transparent. To this end, we have written out our methodological reflections, decisions, and choices. During the fieldwork, the researcher also used the notes to develop and elaborate on her reflections. In addition, the data was triangulated through fieldwork in two preschools by including different participants and by conducting the fieldwork at different points in time (Twining \& Heller, 2017). We also used two supplementary methods, observations and field notes, and discussed our strategies and experiences of data collection and analysis with other researchers throughout the study.

Ethical considerations are crucial in research. This study was approved by the Norwegian Center for Research Data (NSD) and received the written consent of the children's parents and the preschool staff prior to their participation. The children were informed about the project and assured that they could tell us to stop filming at any point if they wanted to. None of the children asked the first author to stop filming. The children's and preschool staff's names are fictitious.

\section{Findings}

We will in this part investigate three situations: "Boxing training," "Firefighter play," and "The buttock game". These three situations highlight, in various ways, what we found to be characteristic of the apparently new and unexpected playful shared movements. We have sorted the characteristics into two themes: habits, imaginings, transformation and excitement and a moment of shared feelings. The discussion is organized around these themes. The first situation; boxing training, highlights how imaginings and transformations seem to be important for children's creation of moments where they can share feelings and be exited. The second situation; firefighter play, highlights how a moment of shared feelings seemed crucial for the opening up towards bodily challenges. And the third situation highlights how shared purpose of the play seemed to be the decisive for the excitement and the moment of meeting between children with different movement habits and skills. With these three examples, we wish to make the analysis process transparent. However, highlighting some of the situations most probably also made us highlight some of the aspects of the new and unexpected playful shared movements on the expence of others. For instance, the relation 
between the preschool staff and the child is given attention in "Firefighter play", even though there were few situations in the empirical materiale where the preschool staff was engaged in children's playful shared movements.

\section{Boxing training}

The first situation occurs when the children have been in free play on the playground for a while and involves two boys, John and Jack, who had found a piece of vinyl the size of an A4 sheet. The first author had previously observed John using the piece of vinyl as an iPad, but in this instance the boys held it and looked at it. Suddenly, as Jack was holding it, John began hitting and kicking at it. The boys figured out that they could imagine they were boxers and that the piece of vinyl was a boxing pad:

Jack holds the piece of vinyl in his hands while John hits and kicks it. Sometimes John turns around before he hits and kicks. Jack encourages John, telling him that he is doing it well and urging him on. After a while they switch roles. John holds the vinyl while Jack hits and kicks. John gives him advice on how to attack it. Sometimes Jack turns around before he hits and kicks.

This activity lasted for about 10 minutes, with John and Jack taking turns being the boxing trainer and the one who practiced boxing. It seemed like the boys had transformed the piece of vinyl into a boxing pad, thereby creating a new now moment for themselves. This transformation dramatically changed how they moved in conjunction with the "new" piece of equipment, the boxing pad. A tension between the boxer and trainer holding the boxing pad emerged. When the trainer moved slightly to the right, the boxer moved accordingly to his left and hit the pad swiftly. The tension was thus resolved, but as the trainer moved again, new tensions emerged, leading to new coordinated movement patterns between the children. It was like a dance. We are remined here of the famous quote from Muhammed Ali, "Float like a butterfly, sting like a bee." Put in terms of Stern's (2010) notion of vitality forms, it seemed like the children went from a fading to an exploding and pulsing vitality form.

With few words, John and Jack adapted their body's movement to match the other. The switch in role from boxer and trainer seemed important for this synchronization. They appeared to have an agreement in which the imaginary boxing pad was the coordinating element. When Jack was the trainer, he encouraged John to develop his boxing moves in an increasingly complicated way. With deep concentration and excitement, the two boys" bodies "danced" together. They appeared to have a moment of meeting where they regulated each other's emotional state and held each other in a pulsing vitality form with an open body posture. They repeated these movements with small changes, sharing a common rhythm. They opened each other up to creativity and change.

\section{Firefighter play}

The next situation involves Joachim and his discovery of Howard and Isak's firefighter activity. Howard and Isak often imagined that a large playground structure 
was a fire station and that they were firefighters extinguishing fires. In this activity, they moved with definite, intensive movements and talked with deep voices, and they imagined that the playground structure contained sirens and had a fire pole.

Joachim, on the other hand, most often played football. But one day, while participating in a football match, he suddenly placed the ball on the ground, sat down on it and turned his body towards Howard and Isak's firefighter play. The first author observed him doing this several times. Then, suddenly, he went from opening his body in an observational way to opening his body to the movements of the play activity:

Joachim walks up the stairs to the large playground structure and starts slowly practicing the movements of the firefighter fantasy play. Andrew, preschool staff, stands under the play equipment, watching and offering small comments. When Joachim comes to a pole that goes all the way to the ground, he tells Andrew, "I'm not doing that" (sliding down). Andrew speaks quietly to Joachim, but Joachim still holds his arms and legs hard around the pole. Then Andrew stretches his arms toward Joachim. Joachim spins around the pole and into Andrew's arms. After sitting on the ground for a while, Joachim does it all over again. When he reaches the pole, he slides all the way down to the ground by himself. He then runs around and extinguishes fires.

By transforming their bodies and the playground structure, Howard and Isak created tensions, challenges, and excitement that interrupted Joachim's football habits and created a now moment for him. He began to move differently in relation to the playground structure and the playground. He suddenly was climbing the big play equipment as a firefighter and pulling himself towards a pole that was about two meters from the ground. This was most likely an extreme challenge for him. He had created an exploding vitality form for himself.

Despite the fact that the movements were challenging for him, Joachim slowly and unsteadily, yet persistently, imitated the other boys. Andrew, by turning his body towards Joachim and making small comments, participated in the latter's movements. Andrew, in an almost imperceptible way, appeared to share a moment of meeting with Joachim.

But when Joachim reached the sliding pole, he seemed worried about his next movement. He clung to the pole, refusing to slide down. His body posture was closed, and he appeared on the verge of withdrawing from the activity. Andrew's calm words and his gesturing towards Joachim with outstretched arms seemed to open Joachim's body to the challenge and the movement. Joachim loosened his grip on the pole and opened his body towards Andrew. Andrew's act probably made it possible for Joachim to incorporate the rhythm of the firefighter play in his body and thereafter in his interaction with Howard and Isak. Andrew had created a moment of meeting that led to change.

\section{The buttock game}

The last situation involves a game of tag started by Howard. Before this situation occurs, Howard and Sarah have walked around on the playground for a while, not playing with each other or other children. Then suddenly: 
Howard hits Sarah on the buttocks, then runs up a hill and climbs high in a tree. Sarah runs after him, grabs one of the branches, puts her legs around it and pulls herself up. The branch sways up and down when Sarah moves, and it is hard for her to maintain her balance. Slowly pulling herself along it with a lot of effort, she reaches the end of the branch. Howard drops one of his legs down to Sarah and asks if she can catch it. When she tries, he quickly pulls it away. Then he grabs one branch with his hands, puts his legs on another and begins lifting his body up and down, announcing, "I'm doing pullups."

Howard's hit and run most probably created a tension between himself and Sarah. His hitting Sarah started the competition and excitement between the two. The playground became a place where Sarah was using her body to chase Howard, running after him with intense and fast movements, both children laughing and screaming. Howard's slap apparently created an exploding vitality form and a now moment for them.

When they reached the tree, Howard climbed it expertly, laughing and shouting. Sarah, on the other hand, moved slowly in silence, struggling along the branch closest to the ground. Howard was accustomed to climbing the tree and went up quickly; he then performed pull-ups with his legs on one branch while his arms held another. $\mathrm{He}$ and Sarah met the challenges presented by the tree with different habits and expressed an open body posture and an "I can" attitude towards different movement challenges.

Nevertheless, the tension between them continued and a moment of meeting emerged. The competition element made them become attuned to each other despite the fact that their movements and bodily rhythms differed. Even though Sarah struggled on the branch closest to ground, she was trying to catch Howards leg. It was as though they were engaged in a kind of unrhythmic dance, and the competition - the struggle to not become the chaser - seemed to make them regulate each other's emotions to maintain an open body posture.

\section{Discussion}

In the analysis, we have used the concepts now moment, moment of meeting, vitality form and open and closed body posture to interpret three situations from the video observations. In this section, we will discuss the findings using previous research and theoretical approaches to play, movement, and moments.

\section{Habits, imaginings, transformation, and excitement}

The findings suggest that the new and unexpected playful shared movements are structured to achieve a common unarticulated imaginative purpose. In the first situation, the children's aim is to be boxers and boxing trainers and to develop their boxing skills; in the second it is to move like a firefighter and use the big play equipment as a fire station; in the third scenario, the aim is to hit the other on the buttocks so he or she becomes the chaser. The situations indicate, in line with Kristensen and Greve's (2018) findings, that the imaginative purpose was the coordinating element. This 
underlines Mårtenson’s (2004) argument that play is not as purposeless as it may seem to us adults. It is structured to produce symbolic transformations (Flanningan \& Dietze, 2017). In addition, we will argue that the fact that play include children in targeted symbolic transformations seemed to create now moments for the children. It is like the imaginative purpose of play connect children's bodies, emotions and minds, and opens up an opportunity for them to participate in what Husserl (2004, p. 43) conceptualizes as each others' experiences, intentions and lifeworlds.

At the same time as the playful shared movements are structured to achieve a common goal, they seem to promote the children's exploration of their habits in their own creative way, as Joachim did in the firefighter play and John and Jack in the boxing training. In these activities, the boys's normally practiced their "new professions" in a calm and repetitive way where they regulated each other's challenges in a shared emotional field. But suddenly, new tensions in the situations tend to emerge and the boys were either further drawn into the activities with a much stronger sense of engagmenet and agency, or they could become more detached and distanced to the whole situation. We are remined here about how a pulsing vitality of reciprocal relations may explode into further exploration together or simply fade away. We see the fluctuations in vitality forms as a window of opportunity to understand how the emotional overlap between children varies in playful movement activities, and that the variation expresses an ongoing reorganization of the intersubjective field between the children and their purposive play and imaginings.

So, when John and Jack transformed their bodies to become boxers and boxing trainers, their shared imaginings and excitement of the situation seemed to foster bodily rhythms that both challenged and surprised the children's habitual relations. This is in line with Bjørgen and Svendsen (2015) and Haywood-Bird's (2017) arguments that social relations motivate movement play and physical challenges. While we agree, we would expand this position with Stern's (2010) concept vitality form, and argue that the shared imaginings, transformations, and excitement challenged the regulation between the exploding, pulsing and fading vitality form. Being free to imagine and transform based on their own habits seemed crucial for the children to experience now moments and for the now moments to become moments of meeting. However, play and movement in themselves do not always result in creativity, growth, and moments of meeting. Whether or not these things occur appears to depend on how emotionally attuned participants in play are to each other.

\section{A moment of shared feelings}

The now moment when Joachim comes to the fire pole is a moment where a fading vitality form emerges. It is at this point that Joachim's firefighter movements might have stopped. Andrew's bodily attunement to Joachim was probably what changed Joachim's vitality form from fading to exploding. Even though Andrew did almost nothing, it was everything that was needed for this to be a moment of growth and change for Joachim. 
Inspired by Stern (2007), we argue that Joachim experiences growth and change not only in his movements but also in terms of his emotional bond with Andrew. It was their emotional attunement that most likely relieved Joachim's distress. This is an illustration of Morris' (2004, p. 162) claim that a change from distress to the absence of distress leads to an open body posture and a change in a person's understandings of himself, others, and the surroundings. Joachim's participation in the firefighter play introduced new movements and social possibilities for him. In addition, the relationship between Joachim and Andrew also most probably developed. This example expands our understanding of what several researchers have found before, namely that teachers' involvement in play is positive for children's movement opportunities (Bjørgen, 2016; Bjørgen \& Svendsen, 2015; Hagen, 2015). Morrissey, Scott \& Rahimi (2017) highlight how important it is for children's growth and change that preschool teachers are attuned to the children's playful situations. In addition, Andrew's actions illustrate how important it is for the preschool staff to spot the small shifts when now moments are in the verge of withdrawal and the child's vitality form is fading. The example with Joachim and Andrew highlights the value of a shared emotional moment for Joachim's opportunity to develop his movements and later participate in play with Howard and Isak.

Nevertheless, what the situations presented in the article and the other situations we have analyzed show best is how important interactions between children are for creating now moments and moments of meeting. In the boxing training activity, for example, John and Jack seemed to encourage each other to continue with words and body language, creating new now moments and stimulating each other's creativity. In the dance between their bodies, John and Jack seemed to spot each other's small and almost invisible shifts between the fading, pulsing and exploding vitality form and regulate each other's movements and emotions. That they could imagine together seemed to open up not only the space between the real and the imaginative world, as Kristensen and Greve (2018) claim, but also the space between their emotional worlds.

In the buttock game, Sarah and Howard appeared to experience a moment of meeting, even though they moved their bodies with different rhythms. The excitement of the competition seemed to open up a moment for them where they could regulate each other's movements and emotions. The thrilling emotions created by the distinctive character of the buttock game seemed to bind the two children bodily and emotionally. We argue that this illustrates that not only does emotional attunement lead to bodily challenges and moments of meeting, but bodily challenges also lead to thrilling emotions (Sandseter \& Kennair, 2011) and the creation of moments of meeting.

Stern $(2007$, p. 236) has used the concept of a shared feeling voyage to describe the shared experience of a moment of meeting and the metaphor of traveling through a shared feeling landscape to describe what makes the moment of meeting creative and expansive. We find this to be a metaphor for the moments of meeting we have analyzed. The shared feeling voyage is evident in the moment shared by Andrew and Joachim 
at the fire pole, in the moment when John and Jack got the idea that the piece of vinyl could be a boxing pad, and in the moment when Howard hit Sarah on her buttocks. These are all moments when the children opened up their bodies to handle a challenge and experience growth. We argue that this is an illustration of why the emotional moods children create are essential to determining what kind of play they can experience (Karoff, 2013).

\section{Concluding remarks}

The situations analyzed in this article indicate that playful shared movements have some characteristics that promote the creation of now moments. The imaginings, transformations, and excitement of play and movement seemed to introduce new, unexpected, worrisome and problematic elements, which Stern (2007, p. 169-180) argues are essential for now moments. In the breakdown of habitual movements, the emotional attunement between bodies and the act of being in the present seemed to be crucial for the creation of a moment of meeting.

Based on these findings, we will argue that to raise preschool teachers' knowledge about the intrinsic value of play, and how they can move to create playful shared movements, probably will raise children's opportunities to growth and change more than an increased amount of organized and sedentary activities.

In this study we have focused on the dynamical shifts from now moments to moments of meeting that occur in play scenarios on preschool playgrounds. These dynamical shifts can be huge and visible, but most often they are small and difficult to spot. Children live in these dynamical shifts all the time and experience them from their first person perspectives in peer-relations. As adults, e.g., parents, pre-school staff or researchers, we have another access to them. We see them from the "outside". It is fairly easy to notice the huge dynamical shifts between children, such as when they suddenly become deeply involved and excited in a task or when a child was left out of play. But it is much harder to see the small dynamical shifts in childrens's playful movement activities. It requires an interest and a lens of understanding them.

Our aim have been to visualize the shifts from now moments to moments of meeting by in-depth analysis of playful shared movement situations. We experience this as the strength of the study. The limitation of the study is that we have explored these shifts through video-observations, and not by involving the children actively in the research process. In forthcoming studies children should be more actively involved, for instance by conducting additional video-observations, taking photographs or being included in the analysis-process.

\section{Acknowledgements}

We greatly appreciate the participation of the children and preschool staff in this study and the discussions of this content with prof. Anne Greve. We also thank the two anonymous reviewers for helpful comments. 


\section{Author biography}

Lillian Pedersen has a Ph.D. in Educational Sciences for Teacher Education and is an assistant professor at the Faculty of Education, Arts and Sports at the Western Norway University of Applied Sciences (HVL). Her research focuses on children, movement and identity, and her teaching and supervision experiences is related to play, movement, child development and children as citizens.

Vegard Fusche Moe, professor of sports science at the Western Norway University of Applied Sciences (HVL), Faculty of Teacher Education, Arts and Sports. He has a strong research interest in movement, body and learning processes in context such as sports and education.

\section{References}

Alexander, S. A., Frolich, K. L., \& Fusco, C. (2014). "Active play may be lots of fun, but it's certainly not frivolous": The emergence of active play as a health practice in Canadian public health. Sociology of Health E Illness 36(8), 1188-1204. https://doi.org/10.1111/1467-9566.12158

Alexander, S. A., Fusco, C., \& Frolich, K. L. (2015). "You have to do 60 minutes of physical activity per day ... I saw it on TV": Children's constructions of play in the context of Canadian public health discourse of playing for health. Sociology of Health E Illness 37(2), 227-240. https://doi.org/10.1111/1467-9566.12179

Bjørgen, K. (2012). Fysisk lek i barnehagens uterom. 5-åringers erfaring med kroppslig fysisk lek i barnehagens uterom. Nordisk barnehageforskning, 5(2), 1-15. https://doi.org/10.7577/nbf.418

Bjørgen, K. (2016). Physical activity in light of affordances in outdoor environments: Qualitative observation studies of 3-5-year-olds in kindergarten. SpringerPlus, 5(1): 950. https//doi.org/10.1186/s40064-0162565-y

Bjørgen, K., \& Svendsen, B. (2015). Kindergarten practitioners' experience of promoting children's involvement in and enjoyment of physically active play: Does the contagion of physical energy affect physically active play? Contemporary Issues in Early Childhood, 16(3), 657-671. https://doi.org/10.1177/1463949115600025

Braun, V., \& Clarke, V. (2006). Using thematic analysis in psychology. Qualitative Research in Psychology, 3(2), 77-101. https//doi.org/10.1191/1478088706qp063oa

Corsaro, W. A. (2003). We're friends, right? Inside kids' culture. Joseph Henry Press.

Fangen, K. (2010). Deltagende observasjon. Fagbokforlaget.

Flanningan, C., \& Dietze, B. (2017). Children, outdoor play, and loose parts. Fournal of Childhood Studies, 42(4), 53-60. https://doi.org/10.18357/jcs.v42i4.18103

Gadamer, H-G. (1975/2006). Truth and method. Continuum.

Hagen, T. L. (2015). Hvilken innvirkning har barnehagens fysisk utemiljø på barns lek og det ansattes pedagogiske praksis i uterommet. Nordic Early Childhood Education Research fournal, 10(5), 1-16. https://doi.org/10.7577/nbf.1430

Haywood-Bird, E. (2017). Playing with power: An outdoor classroom exploration. Early Child Development and Care, 187(5-6), 1015-1027. https://doi.org/10.1080/03004430.2016.1223070

Husserl, E. (2004). Ideas: General Introduction to Pure Phenomenology. Routledge.

Karlsen, L., \& Lekhal, R. (2019). Practitioner involvement and support in children's learning during free play in two Norwegian kindergartens. Fournal of Early Childhood Research, 17(3), 233-246. https://doi. org/10.1177/1476718X19856390

Karoff, H. S. (2013). Play practices and play moods. International fournal of Play, 2(2), 76-86. https://doi.org/ $10.1080 / 21594937.2013 .805650$

Kristensen, K. O. \& Greve, A. (2018). Dramatic play - Modelling teachers' interactions in kindergartens. In T. Haugen \& K. I. Skjerdingstad (Eds.), Children and young people, aesthetics and special needs. An interdisciplinary approach (pp. 291-309). Vidarforlaget.

Løkken, G. (2012). Levd observasjon. En vitenskapsteoretisk kommentar til observasjon som metode. Cappelen Damm Akademisk. 
Løndal, K. (2010). Revelations in bodily play. A study among children in an after-school programme (Doctoral dissertation, The Norwegian School of Sport Sciences). NIH. http://hdl.handle.net/11250/171291

Merleau-Ponty, M. (2012). Phenomenology of perception. Routledge.

Morris, D. (2004). The sense of space. SUNY Press.

Morrissey, A-M., Scott, C., \& Rahimi, M. (2017) A comparison of sociodramatic play processes of preschoolers in a naturalized and a traditional outdoor space. International fournal of Play, 6(2), 177-197. https://doi.org/ $10.1080 / 21594937.2017 .1348321$

Moser, T., \& Martinsen, M. T. (2010). The outdoor environment in Norwegian kindergartens as pedagogical space for toddlers' play, learning and development. European Early Childhood Education Research fournal, 18(4), 457-471. https://doi.org/10.1080/1350293X.2010.525931

Mårtenson, F. (2004). Landskapet i leken. En studie av utomhuslek på förskolegården (Doctoral dissertation, Swedish University of Agricultural Sciences). Epsilon Open Archive. https://pub.epsilon.slu.se/803/1/ Fredrika20050405.pdf

Petrie, K., \& Clarkin-Phillips, J. (2018). "Physical education" in early childhood education: Implications for primary school curricula. European Physical Education Review, 24(4), 503-519. https://doi.org/ $10.1177 / 1356336 \times 16684642$

Robertson, N., Morrissey, A-M. \& Moore, D. (2019). From boats to bushes: Environmental elements supportive of children's sociodramatic play outdoors. Children's Geographies, 18(2), 1-13. https://doi.org/10.1080/ 14733285.2019 .1630714

Sandseter, E. B., \& Kennair, L. E. (2011). Children's risky play from an evolutionary perspective: The anti-phobic effects of thrilling experiences. Evolutionary Psychology, 9(2), 257-284. https://doi.org/ 10.1177/147470491100900212

Stern, D. N. (2007). Her og nå. Øyeblikkets betydning i psykoterapi og hverdagsliv. Abstrakt Forlag.

Stern, D. N. (2010) Forms of vitality: Exploring dynamic experience in psychology, the arts, psychotherapy, and development. Oxford University Press.

Sutton-Smith, B. (1997/2001). The ambiguity of play. Harvard University Press.

Twining, P., \& Heller, R. S. (2017). Some guidance on conducting and reporting qualitative studies. Computers E Education, 106, A1-A9. https://doi.org/10.1016/j.compedu.2016.12.002

UN Committee on the Rights of the Child [CRC]. (2013). General comment No. 17 (2013) on the right of the child to rest, leisure, play, recreational activities, cultural life and the arts (art. 31). https://www.refworld.org/ docid/51 ef9bcc $4 . h t m l$

Walsh, D., Bakir, N., Lee, T. B., Chung, Y.-H, Chung, K., Campuzano, H., ... Waight, N. (2007). Using digital video in field-based research with children. In J. A. Hatch (Ed.), Early childhood qualitative research (pp. 43-62). Routledge.

Winnicott, D. W. (2005). Playing and reality. Routledge.

World Health Organization [WHO]. (2019). Guidelines on physical activity, sedentary behaviour and sleep for children under 5 years of age. https://www.who.int/publications-detail/guidelines-on-physical-activitysedentary-behaviour-and-sleep-for-children-under-5-years-of-age 